\title{
Medicolegal Review: Perinatal Effexor Lawsuits and Legal Strategies Adverse to Prescribing Obstetric Providers
}

\author{
Nathan Kirsch, BS ${ }^{1}$ Luis D. Pacheco, MD ${ }^{2,3}$ Amjad Hossain, PhD ${ }^{2}$ John Y. Phelps III, MD, JD, LLM² \\ ${ }^{1}$ Medical School, The University of Texas Medical Branch at Galveston \\ Galveston, Texas \\ 2 Department of Obstetrics and Gynecology, The University of Texas \\ University Boulevard, Galveston, TX 77555-0587 \\ Medical Branch at Galveston, Galveston, Texas \\ ${ }^{3}$ Department of Anesthesiology, The University of Texas Medical \\ Branch at Galveston, Galveston, Texas \\ Address for correspondence John Y. Phelps, MD, JD, LLM, 301 \\ (e-mail: jyphelps@utmb.edu).
}

Am J Perinatol Rep 2019;9:e88-e91.

\begin{abstract}
Keywords

- Effexor

- pregnancy

- learned intermediary

- obstetric

- lawsuit

- liability

- informed consent

Objectives This study was aimed to familiarize obstetricians with the legal environment surrounding Effexor lawsuits and emphasize the importance of documenting informed consent in the medical records when prescribing a medication that is being targeted for litigation.

Study Design We used the LexisNexis legal search engine to review legal documents from Effexor-related cases and also used Google to search for Effexor-related lawsuits online, further researching these cases via publically available court records from district clerk offices. Finally, we conducted a year-by-year literature review from 1993 to 2017 to establish the history and evolution of scientific studies surrounding Effexor use during pregnancy.

Results Litigation involving Effexor typically arises due to congenital cardiac birth defects in the neonate allegedly associated with maternal Effexor use in pregnancy. Medication manufacturers have employed a legal strategy termed the learned intermediary doctrine in an attempt to shift liability away from themselves and on to prescribing obstetricians. Manufacturers claim they adequately inform obstetricians of the risks and benefits of prescribing their product and it is the duty of the obstetrician to relay those risks and benefits to their patients.

Conclusion To reduce the risk of liability exposure, obstetricians must adequately document informed consent in the medical records when prescribing medications to their pregnant patients.
\end{abstract}

The use of antidepressant medications, such as Effexor, a serotonin-norepinephrine reuptake inhibitor (SNRI), and other antidepressant medications like it, including selective serotonin reuptake inhibitors are considered the mainstay of treatment for major depressive disorder (MDD). In many cases, the use of these medications can reduce or completely eliminate the mood symptoms associated with MDD. Unfortunately, cessation of these medications prematurely, as may occur in pregnant patients, often has a detrimental impact upon maternal and fetal outcomes including increased rates of miscarriage, small for gestational age babies, preterm delivery, intra uterine growth restriction, and fetal death. Furthermore, use of these medications during pregnancy may lead to adverse fetal effects including ventricular-septal (VSD) and atrial-septal (ASD) defects. ${ }^{1}$ Women whose children suffer ASDs or VSDs as a result of alleged exposure to received

December 19, 2017

accepted after revision

October 12, 2018
DOI https://doi.org/

10.1055/s-0039-1678723. ISSN 2157-6998.
Copyright $\odot 2019$ by Thieme Medical

Publishers, Inc., 333 Seventh Avenue, New York, NY 10001, USA. Tel: +1(212) 584-4662.
License terms

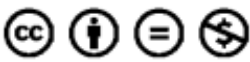


Effexor in utero often seek recourse via the legal system, the frequency of which has been enhanced by the abundance of legal advertisements specifically targeted at those who have been affected by the use of Effexor while pregnant. Prescribing obstetric providers, medication manufacturers and other parties associated with the medication manufacturer have been the subjects of these suits, with any of the above parties being named. Obstetric providers prescribing Effexor to their pregnant patients should be knowledgeable regarding the use of the learned intermediary doctrine, a legal concept employed by the medication manufacturer's legal counsel, to shift liability away from the drug manufacturer, and onto to the prescribing obstetric provider.

Understandably, the legal proceedings regarding the use of Effexor during pregnancy may discourage obstetric providers from prescribing it to their pregnant patients, albeit to the detriment of the mother and fetus, both of whom may benefit from its use. It is not the intent of this medicolegal review to deter obstetric providers from prescribing Effexor or other antidepressants that may be needed in pregnancy to adequately manage MDD; however, prescribing obstetric providers should be aware of the legal strategies used by medication manufacturers and understand the importance of adequately documenting informed consent when prescribing medications that are being targeted for litigation.

\section{Materials and Methods}

We used the LexisNexis legal search engine to review legal documents from Effexor-related cases. LexisNexis is a legal database used by attorneys, judges, paralegals, and law students to find past cases that reinforce legal arguments. We also searched for Effexor-related lawsuits using the Google search engine and further researched these cases via publically available court records from district clerk offices.

We conducted a review of the literature, via PubMed and Ovid-Medline, from 1993 to 2017 in a stepwise year-by-year fashion to adequately establish the history of use of Effexor.

\section{Results}

\section{History of the Use of Effexor in Pregnancy and its Complications}

In 1993, the U.S. Food and Drug Administration (FDA) approved Effexor for the treatment of MDD and a myriad of other psychiatric conditions. Initial studies conducted by the medication's manufacturer, Wyeth Pharmaceuticals, Inc. (Collegeville, PA, USA), indicated that there was no correlation between fetal Effexor exposure during the first trimester and rates of birth defects. However, their study did note an association between discontinuation of the medication during the second and third trimesters of pregnancy and a withdrawal syndrome in the neonate. ${ }^{2}$ Using data collected from the FDA Adverse Events Reporting System (FAERS), Wyeth Pharmaceuticals, Inc., further characterized this withdrawal syndrome, via postmarketing studies, as neonatal "agitation, colic, drowsiness, and dyspepsia, increased startle, jitteriness, sleeplessness, and seizure in infants coin- cident with venlafaxine use by their mothers." ${ }^{3}$ The results of this study, supported by other multicenter studies, ${ }^{4}$ prompted the FDA to issue a revision of Effexor's product label to include severity warnings about the neonatal withdrawal syndrome.

Consequent studies sought to establish whether or not Effexor and its major biologically active metabolite, O-desmethylvenlafaxine (ODV), could transfer transplacentally between mother and fetus. The initial studies submitted to the FDA established adverse fetal effects without a clear correlation ${ }^{5}$ and pertained primarily to the aforementioned withdrawal effects noted in the newborn. It was not until 2000, 7 years after Effexor began being used in pregnant women that clear evidence of transplacental transmission of venlafaxine and ODV was established, ${ }^{6}$ albeit without any clear neonatal effect.

After confirming that Effexor and ODV could cross the placenta, many studies sought to establish the effects the drug had upon organogenesis during the first trimester. The first evidence that Effexor and ODV may cause teratogenic effects came about in 2012, when a study analyzing the correlation between Effexor exposure during the first trimester and congenital birth defects was published. This study revealed that exposure to Effexor within the first trimester of pregnancy was positively associated with congenital defects of the heart, lungs, neural tube structures, and bowels. ${ }^{7}$

\section{The Learned Intermediary Doctrine}

When a lawsuit is filed against a medication manufacturer, the manufacturer may employ a legal strategy called the learned intermediary doctrine to attempt to absolve itself of responsibility in the lawsuit and shift liability onto the obstetric provider who prescribed the medication. The premise of the learned intermediary doctrine is that the manufacturer of a product has fulfilled its duty of care when the necessary information is provided to a "learned intermediary," such as a prescribing obstetric provider who is then responsible for disseminating that information to the consumer; in this case, the patient. Even if the plaintiff's attorney (s) representing the patient does not name the obstetric provider in the lawsuit, the defendant's attorney(s) representing the manufacturer may join the prescribing obstetric provider in the lawsuit and then attempt to shift all liability onto them using the learned intermediary doctrine.

A product liability lawsuit heard in 2013 involving Effexor and congenital heart defects ${ }^{8}$ demonstrates use of the learned intermediary doctrine by manufacturers in an attempt to shift responsibility away from themselves and on to the prescribing obstetric provider. Briefly, the plaintiffs brought a suit against the medication manufacturer's parent company and their distributor because of congenital heart defects found in their child that were allegedly associated with his mother's use of Effexor during pregnancy. This case was ultimately dismissed but Pfizer Inc. (New York, NY, USA) attempted to absolve itself, Wyeth Pharmaceuticals Inc. (purchased by Pfizer in 2009), and their distributor, McKesson Corporation (San Francisco, CA, USA), of any fault by asserting the learned intermediary doctrine. They argued that the prescribing obstetric provider, 
as an actor who understood both the patient's medical history and the risks and benefits of using Effexor during pregnancy, was responsible for advising the patient about the medication's use while pregnant.

Understanding how the learned intermediary doctrine can be used to shift liability is particularly important in a legal environment in which obstetric providers prescribing Effexor are being named in lawsuits. In 2011 to 2012, a suit was brought against Wyeth Pharmaceuticals Inc., Pfizer Inc., CVS Pharmacy (Woonsocket, RI, USA), Caremark RX (Lee's Summit, MO, USA), and later, the dispensing pharmacist and the prescribing obstetric provider as codefendants, by the parents of a woman who suffered congenital heart defects allegedly secondary to Effexor exposure in utero. ${ }^{9}$ The suit was ultimately dismissed but naming the prescribing obstetrician as a defendant in such a case illustrates the legal exposure obstetric providers may face when prescribing Effexor during pregnancy. Wyeth Pharmaceuticals Inc., and their parent company Pfizer Inc., chose to use the learned intermediary doctrine in defending Effexor lawsuits, arguing that the liability lies with the prescribing obstetric provider. ${ }^{10}$ It is paramount that prescribing obstetric providers understand how liability in legal cases like this can be shifted onto them via the learned intermediary doctrine, particularly when companies have done so numerous times previously. ${ }^{11-15}$

Pharmaceutical companies employing a defense strategy centered upon the use of the learned intermediary doctrine risk deterring obstetric providers from prescribing their products to patients in the future, consistent with the old idiom that "you should not bite the hand that feeds you." Sensibly, if obstetric providers are aware of the efforts of medication manufacturers to shift liability to them, they may choose to discontinue prescribing those medications to their patients. Patients may be harmed when obstetric providers are reluctant to prescribe a needed medication subject to ongoing litigation; pharmaceutical companies risk financial consequences that greatly outweigh the costs incurred attempting to defend a lawsuit.

\section{Potential Causes of Action against Obstetric Providers}

It would not be unreasonable to think that obstetric providers in clinical practice are unaware of the learned intermediary doctrine and the legal strategies employed by pharmaceutical manufacturers and their legal counsel. There are two claims a plaintiff can make against an obstetric provider who prescribes medication: negligence for prescribing a medication that causes harm to a patient and failure to obtain adequate informed consent. To fulfill the criteria for medical negligence, a plaintiff will have to objectively prove the obstetric provider deviated from the acceptable standard of medical care by prescribing the medication and that this deviation was directly responsible for the patient's injury. This may be a difficult burden for a plaintiff patient to prove when an obstetric provider prescribes an FDA-approved medication for its intended use, such as using Effexor during pregnancy to manage MDD. For this reason, plaintiff's attorneys often choose to pursue the alternative claim for failure to obtain informed consent.
There are also two standards for failure to obtain informed consent: the prudent obstetric provider standard and the reasonable patient standard. The standard applied will depend upon the jurisdiction in which the lawsuit is being litigated. The prudent obstetric provider standard is the majority standard applicable in most states. ${ }^{16}$ The prudent obstetric provider standard is what a reasonably prudent obstetric provider would have disclosed to a patient under similar circumstances. Disclosure should include the theoretical risks associated with exposure to Effexor during pregnancy, including the limitations of the available data, that is, that many studies are plagued by recall bias, as well as the risks for the patient and her fetus associated with untreated depression during pregnancy. This claim requires expert testimony by an obstetric provider as to what a prudent obstetric provider should disclose to a patient. The other standard is the reasonable patient standard and requires the obstetric provider to disclose those risks a reasonable patient would want to know, including medication risks and the alternatives to the medication. The reasonable patient standard is the minority standard and unlike the prudent obstetric provider standard, does not require expert testimony. ${ }^{17}$

\section{Discussion}

The authors of this medicolegal review believe Effexor to be a relatively safe and efficacious medication for use in combatting the symptoms of MDD and the other psychiatric conditions for which the FDA has approved it. We also believe that Effexor, and other antidepressant medications like it, should continue to be prescribed for their FDA-approved purposes despite current litigation. Although the focus of this paper is on Effexor, no medications prescribed to combat the symptoms of MDD are free from medical risks to patients or legal risks to the prescribing obstetric providers.

Regardless of the jurisdiction and whether the majority or minority standard for informed consent is used, obstetric providers need to be especially diligent in documenting in the medical records that they informed the patient of the risks associated with use of the prescribed medication. In the case of Effexor, risks such as congenital birth defects and neonatal withdrawal syndrome associated with Effexor use during pregnancy should be discussed and documented. Documentation in the medical record is particularly important in cases where the prescribed medication is the subject of legal scrutiny or the medication manufacturer has previously asserted the learned intermediary doctrine in an attempt to shift liability away from them and onto obstetric providers.

Adequate documentation in the medical records is of the utmost importance to protect providers when pharmaceutical companies and manufacturers of medications attempt to shift liability for adverse outcomes to the prescribing obstetricians. An instance in which informed consent was obtained should be documented explicitly in the medical records and if possible, should include a written statement that the patient has been informed of and understands the approximate 1.5 to 2 -fold risk of congenital cardiopulmonary defects $^{18,19}$ and neonatal withdrawal syndrome associated 
with Effexor use in utero as compared with other antidepressant medications for treatment of MDD symptoms.

Patients who are pregnant or plan to become pregnant should be informed of the risk of neonatal congenital birth defects of the heart (odds ratio [OR]: 2-3), lungs (OR: 1.5-2), bowels (OR: 3.8 ), and neural tube-derived structures (OR: 5.6) that have been associated with maternal Effexor exposure during pregnancy. ${ }^{7,18}$ Furthermore, patients should be informed of the most recent literature associating maternal Effexor use in pregnancy with persistent pulmonary hypertension in the neonate. ${ }^{18}$

With proper informed consent, patients without contraindications to antidepressant medications who are intolerant of, or receive no benefit from, other antidepressant medications are acceptable candidates for Effexor. In spite of the aforementioned risk of congenital birth defects associated with maternal Effexor use in pregnancy, the prescribing obstetric provider can reduce liability exposure by documenting proper informed consent in the medical records. Regardless of the choice of antidepressant medication, appropriately providing and adequately documenting informed consent, using language common to both the patient and obstetric provider, serves to both inform the patient of the risks, and benefits of their treatment and reduce legal exposure for obstetric providers. By providing and documenting (preferably via written media) informed consent, obstetric providers should be less leery of prescribing antidepressant medications that they feel best fits their patients' medical needs.

\section{Conflicts of Interest}

The authors of this medicolegal review would like to express that they have no affiliations or involvement in any organization or entity with any financial or nonfinancial interest in the subject matter discussed in this manuscript.

\section{Acknowledgments}

We would like to thank the University of Texas Medical Branch at Galveston for providing access to the myriad of scientific journals and the LexisNexis legal search engine, without which this manuscript would not be possible.

\section{References}

1 ACOG Committee on Practice Bulletins-Obstetrics. ACOG Practice Bulletin: Clinical management guidelines for obstetrician-gynecologists number 92, April 2008 (replaces practice bulletin number 87 , November 2007). Use of psychiatric medications during pregnancy and lactation. Obstet Gynecol 2008;111(04):1001-1020
2 Wyeth Pharmaceuticals I. Effexor XR (venlafaxine hydrochloride) extended-release capsules. 2004; Available from: https://www.accessdata.fda.gov/drugsatfda_docs/label/2012/020151s059,020699s100lbl. pdf. Accessed March 13, 2019

3 US Food and Drug Administration. FDA adverse event reporting system (FAERS). Available from: https://www.fda.gov/Drugs/ GuidanceComplianceRegulatoryInformation/Surveillance/ AdverseDrugEffects/. Accessed December 14, 2017

4 Einarson A, Fatoye B, Sarkar M, et al. Pregnancy outcome following gestational exposure to venlafaxine: a multicenter prospective controlled study. Am J Psychiatry 2001;158(10):1728-1730

5 Wyeth Pharmaceuticals, Inc. EFFEXOR-venlafaxine hydrochloride tablet. 2008; Available from: https://www.accessdata.fda.gov/drugsatfda_docs/label/2008/020151s051lbl.pdf. Accessed December 8, 2017

6 Hostetter A, Ritchie JC, Stowe ZN. Amniotic fluid and umbilical cord blood concentrations of antidepressants in three women. Biol Psychiatry 2000;48(10):1032-1034

7 Polen KN, Rasmussen SA, Riehle-Colarusso T, Reefhuis J; National Birth Defects Prevention Study. Association between reported venlafaxine use in early pregnancy and birth defects, national birth defects prevention study, 1997-2007. Birth Defects Res A Clin Mol Teratol 2013;97(01):28-35

8 A.S. v. Pfizer, Inc., Case No.: 1:13-cv-00524 - LJO - JLT (United States District Court, E.D. California 2013). Available from: https://casetext.com/case/as-v-pfizer. Accessed March 13, 2019

9 Emeigh J. Butte parents suing drug company over daughter's birth defects. 2012. Available from: http://billingsgazette.com/news/ state-and-regional/montana/butte-parents-suing-drug-companyover-daughter-s-birth-defects/article_ac18a92f-f5ea-50c3-b7c8-c 2b3d6b691d1.html. Accessed October 29, 2018

10 Friedman RJ. Take two of these and sue me in the morning: efficacy of the learned intermediary doctrine in prescription drug failure to warn cases. St Thomas Law Rev 2010;22(02):276-293

11 Ackermann $v$ Wyeth, 526 F3d 203 (United States Court of Appeals, Fifth Circuit 2008)

12 Strayhorn $v$ Wyeth, 887 F Supp 2d 799 (United States District Court, W.D. Tennessee, Western Division 2012)

13 Simon $v$ Wyeth, 989 A2d 356 (Superior Court of Pennsylvania 2009)

14 Miller v. Pfizer, 196 F. Supp. 2d 1095(United States District Court for the District of Kansas, 2002)

15 Brumley v Pfizer, 149 F Supp 2d 305 (U.S. District Court for the Southern District of Texas 2001)

16 Kapp MB. Patient autonomy in the age of consumer-driven health care: informed consent and informed choice. J Leg Med 2007;28 (01):91-117

17 McNichols v Johnson \& Johnson, 461 F. Supp. 2d 736 (S.D. Ill. 2006). Available from: https://casetext.com/case/mcnichols-vjohnson-johnson. Accessed March 13, 2019

18 Bérard A, Sheehy O, Zhao JP, Vinet É, Bernatsky S, Abrahamowicz M. SSRI and SNRI use during pregnancy and the risk of persistent pulmonary hypertension of the newborn. Br J Clin Pharmacol 2017;83(05):1126-1133

19 Huybrechts KF, Palmsten K, Avorn J, et al. Antidepressant use in pregnancy and the risk of cardiac defects. N Engl J Med 2014;370 (25):2397-2407 